\title{
Rebecca comay, Mourning Sickness. Hegel and the
}

\section{French Revolution}

Stanford University Press, 2011

Jean-Clément Martin

\section{(2) OpenEdition}

Journals

Édition électronique

URL : https://journals.openedition.org/ahrf/13220

DOI : 10.4000/ahrf.13220

ISSN : 1952-403X

Éditeur :

Armand Colin, Société des études robespierristes

Édition imprimée

Date de publication : 1 juin 2014

Pagination : 215-216

ISBN : 978-2-908327-68-7

ISSN : 0003-4436

Référence électronique

Jean-Clément Martin, "Rebecca comay, Mourning Sickness. Hegel and the French Revolution ", Annales historiques de la Révolution française [En ligne], 376 | avril-juin 2014, mis en ligne le 11 juillet 2014, consulté le 01 juillet 2021. URL : http://journals.openedition.org/ahrf/13220 ; DOI : https://doi.org/ 10.4000/ahrf. 13220

Ce document a été généré automatiquement le 1 juillet 2021.

Tous droits réservés 


\section{Rebecca comAY, Mourning Sickness. Hegel and the French Revolution}

Stanford University Press, 2011

Jean-Clément Martin

\section{RÉFÉRENCE}

Rebecca comaY, Mourning Sickness. Hegel and the French Revolution. Stanford University Press, 2011, 202 p., ISBN 978-0-8047-6126-0, 16,83€.

Dans un livre bien connu sur Hegel, le philosophe Charles Taylor (Hegel et la société moderne, parue en 1979 et traduit en français en 1998) disait qu'il y avait deux sortes d'analyses de l'œuvre du philosophe allemand, celles qui sont claires mais qui détruisent leur sujet d'étude et les autres qui en rendent mieux compte, mais qui conduisent leurs lecteurs à se reposer en lisant Hegel dans le texte. Un récent commentateur de Rebecca Comay ajoutait que celle-ci tenait une troisième voie, qui n'était pas médiane. Avouons que nous nous rallierons à cette position, faute d'avoir été capable ni de posséder parfaitement ce livre, ni de trouver un répit en lisant Hegel même traduit. Pourtant le livre de Rebecca Comay mérite qu'on en rende compte, même s'il faut prévenir le lecteur que l'ouvrage n'est pas destiné aux historiens de la Révolution française. Il est donc vain de lui reprocher, comme certains commentateurs l'ont fait, de ne pas parler de Robespierre ou de la Terreur. L'intérêt du livre tient à la lecture de Hegel porteur d'une vision originale de la modernité. Pour la tradition philosophique allemande, la Révolution introduisait certes la modernité politique, mais l'échec des Français à s'en saisir pour établir un régime renvoyait leur insuffisance philosophique, tandis que les Allemands, mûrs philosophiquement, n'étaient pas capables politiquement de s'en saisir, les rendant seulement capables de participer à la restauration de l'ordre - ceci rappelant aussi un jugement de Marx. À partir de ce constat rebattu, Comay propose une lecture psychoanalytique de l'œuvre de Hegel, en s'appuyant sur les notions de deuil, de trauma, de mélancolie, d'incorporation, etc. La 
thèse principale étant que l'idéologie allemande est structurée autour de la mélancolie, née de l'absence de l'objet désiré, pour reprendre un vocabulaire psychoanalytique qui est celui du livre. Définissant l'histoire comme une expérience retardée et vécue au travers des expériences manquées des autres, comme un trauma transgénérationel, elle n'entend pas pour autant faire une lecture psychologique mais bien de dégager la signification philosophique de cette position. Rebecca Comay estime que Hegel, en récusant la tradition allemande illustrée par Kant pour qui la vraie révolution étant morale, ne réussit pas pour autant à sortir des contradictions qu'il dénonce, notamment à propos de la terreur. Rappelons que Kant avait condamné le régicide qui détruisait les principes sur lesquels la révolution devait être fondée. En deçà de la recherche de Hegel pour dégager la rationalité du monde, Rebecca Comay estime que le philosophe fait une lecture de l'histoire en abandonnant une position de jugement de cet échec, mais en intégrant la négation même la liberté dans la fabrication d'une nouvelle conscience collective. D'une certaine façon, elle rejoint Charles Taylor soulignant que Hegel nouait l'héritage des lumières et la primauté de la raison, avec les attentes romantiques autour du sens des expériences communes pour que dans cette conflagration s'exprime la liberté humaine affrontée à ses limites et ses tentations. Il n'y aurait ainsi plus à chercher une misère de la politique ou de la philosophie dans les traditions française ou allemande, mais à voir dans l'œuvre de Hegel (et peut-être malgré ce qu'il dit, mais Charles Taylor avait adopté lui aussi une position critique) le moment où se fait le deuil (mourning) de la révolution et de la raison, au moment même de l'éveil (morning) du monde à la modernité. Concluons en disant simplement d'abord que les premiers chapitres sont plus accessibles que le dernier, ensuite que nul n'est obligé de lire un livre, mais que les interrogations qui sont portées ici méritent d'être méditées par tous ceux qui veulent bâtir des analyses globales sur la période et ses échos européens, enfin que ce compte rendu témoigne simplement des limites personnelles du recenseur. 